$\sqrt{3}$

J. Bio-Sci. 29(1): 93-100, 2021 (June)

ISSN 1023-8654

http://www.banglajol.info/index.php/JBS/index

DOI: https://doi.org/10.3329/jbs.v29i0.54825

\title{
HbA1C VARIABILITY HAS A STRONG RELATIONSHIP WITH PERIPHERAL SENSORY AND MOTOR NEUROPATHY IN TYPE-2 DIABETES MELLITUS
}

\author{
MA Hossain ${ }^{1}$, MK Sarkar ${ }^{2}$, I Mahbub ${ }^{3}$ and SMS Islam ${ }^{1^{*}}$ \\ ${ }^{1}$ Plant Biotechnology and Genetic Engineering Lab., Institute of Biological Sciences, University of Rajshahi, Bangladesh \\ ${ }^{2}$ Department of Neurology, Rajshahi Medical College, Rajshahi, Bangladesh \\ ${ }^{3}$ Department of Endocrinology, Sheikh Hashina National Institute of Burn and Plastic Surgery, Dhaka, Bangladesh
}

\begin{abstract}
Diabetic peripheral neuropathy (DPN) is one of the most common long-term microvascular complications of diabetes. This study was undertaken to investigate the association of $\mathrm{HbA1C}$ variability with diabetic peripheral neuropathy (sensory and motor) in patients with type-2 diabetes. In this study, a total of 150 type-2 diabetic patients were screened for DPN and undergone quarterly HbA1c measurements during the year preceding enrolment were recruited. DPN was confirmed in patients displaying both clinical manifestations of neuropathy and neurological abnormalities assessment. Among the recruited patients, $24 \%$ were found to have DPN (sensory and motor), and these patients also presented with a higher $\mathrm{HbA1c}$ as compared to the patients without DPN $(\mathrm{p}<0.05)$. In addition, the advanced age and longer duration of diabetes were important and significant $(p<0.05)$ risk factors for peripheral neuropathy. Overall study suggests that increased HbA1c level is strongly associated with DPN (sensory and motor) in type-2 diabetic patients and could be considered as a potent indicator for DPN in the recruited patients.
\end{abstract}

Key words: Diabetic peripheral neuropathy, HbA1c, Motor neuropathy, Sensory neuropathy, Type-2 diabetes

\section{Introduction}

Diabetes is the fastest growing non-communicable health problem globally in 21st century. It was estimated that nearly 463 million adult aged 20-79 were suffering from diabetes globally and 8.4 million in Bangladesh in the year 2019. This figure is expected to reach 700 million by 2045 globally and 15 million in Bangladesh (IDF Diabetes Atlas 2019). The prevalence of diabetic complications would rise with increasing rate of diabetes (Thibault et al. 2016). The most prevalent endocrine disease, diabetes mellitus, is characterized by metabolic disorders and micro and macro vascular complications that cause severe morbidity and mortality in the long term (Zargar et al. 1999). 4.2 million people died from diabetes and its complications world-wide in the year 2019 (IDF Diabetes Atlas 2019). Neuropathy is the most common of all complications of diabetes estimated around 60\% (Martin et al. 2014). Diabetic peripheral neuropathy, one of the most frequent microvascular complications of diabetes is related with foot ulceration, amputation and significant quality of life (Carrington et al. 2002, Boulton et al. 2004).

DPN is defined as the occurrence, excluding other factors, of symptoms and/or signs of peripheral nerve dysfunction in people with DM. In DPN, multiple classes of nerves, including sensory, motor and autonomic,

*Author for correspondence: shahinul68@gmail.com 
can be impaired according to American college of foot and ankle surgeons. DPN affects up to half of the diabetic patients for a long run and the burden of DPN has been shown to be significant (Boulton et al. 2005, Tesfaye et al. 2011). Nearly $75 \%$ of diabetic neuropathies are chronic peripheral sensory motor symmetrical neuropathy (Boulton et al. 2006). The most relevant risk factor for predicting DM problems is elevated glycosylated hemoglobin ( $\mathrm{HbA1c}$ ), which is also an indicator of average glycemic scenario over the past 2-3 months.

To minimize the complications of diabetes, managing the level of $\mathrm{HbA1C}$ below $6.5 \%$ is important (International Expert Committee 2009). The variability of HbA1c may be a possible factor, notably sensory and motor neuropathy, associated with DPN risk. Classically, manifestations proceed from the most distal extremities (the fingers and toes) in an asymmetrical fashion that is commonly defined as a distribution of gloves and stocks. Patients usually feel burning discomfort, electrical or stabbing sensations, paresthesia, hyperesthesia, and deep pain, but often they may experience plain numbness, so it is necessary to note that the presence of neuropathy is not excluded from the absence of symptoms. Typically, neuropathic pain is severe at night, and most commonly foot and lower limbs. Foot callus, ulceration and infection can worsen and further turn into distressing and painful disability if no action is taken. Among diabetic patients, foot ulcers are often from Neuropathic origin and hence eminently avoidable (Boulton et al. 2005). Foot ulcers are followed by up to $85 \%$ of amputations in diabetic patients (Boulton 2004). Up to $50 \%$ of DPN may be asymptomatic and patients are at risk of insensate injury to their feet (Mørkrid et al. 2010). There are a few DPN studies from the South-Asian region, where the prevalence of type 2 diabetes and its complications are predicted to rise extensively in the coming years (Wild et al. 2004). From a detailed series of epidemiological studies, it is estimated that the incidence of neuropathy in patients with diabetes is around $30 \%$ in hospital patients and 20\% in community patients (Shaw 1999). Mørkrid et al (2010) and very few other investigators revealed the prevalence of DPN (sensory, motor, and autonomic) in Bangladesh, however to the best of our knowledge; there is no DPN study on the basis of sensory and motor neuropathy in type-2 diabetic patients in Bangladesh.

\section{Materials and Methods}

This study has been carried out from July 2017 to December 2020 in the outpatient department of Rajshahi Diabetic Association General Hospital, Rajshahi, Bangladesh. Total 150 diabetic type-2 patients was included randomly with or without DPN with inclusion (age $>25$, both male and female, patients who fulfilled the WHO criteria of type-2 diabetes mellitus) and exclusion criteria (other known causes of peripheral neuropathy, taking any drug causes peripheral neuropathy, other type of diabetics rather than DM-2). Data was collected by a prescribed data collection sheet with written consent of all individual patients through personal interview, anthropometric measurement, investigation and examination. The HbA1c level was determined using ionic exchange HPLC (IE-HPLC) in the D-10 hemoglobin analysis system (Bio-Rad). DPN was diagnosed in patients displaying both the presence of neurological symptoms and neuropathic symptoms including numbness, tingling, prickling or burning pain in the legs and/or feet and/or upper limbs. Neuropathic signs were defined as reduced or absent ankle jerk reflexes, knee jerk reflexes, biceps reflex, triceps reflex and supinator jerk reflexes (using an appropriate reflex hammer) and reduced or absent distal 
sensation, including vibration perception (using a $128 \mathrm{~Hz}$ tuning fork), touch sensation (using a $10 \mathrm{~g}$ monofilament), thermal discrimination (using cold and warm objects), pinprick sensation (using a pin) and proprioception. Signs were evaluated through careful neurologic examinations. All of the data were articulated as mean $\pm S D$ (standard deviation) of the mean. Data have been analyzed using IBM SPSS software (version 20) and compared by student t-test and $p$-value $<0.05$ was considered as statistically significant.

\section{Results}

The clinical parameters of all participants have been summarized in Table 1. Out of 150 type-2 diabetic patients, 24\% ( $n=36)$ had been confirmed with DPN (sensory and motor). Sensory impairment prevalence $24 \%(n=36)$ found slightly more than motor prevalence $22 \%(n=33)$ though frequency was less. Motor impairment was not absolutely motor, actually mixed of both sensory and motor. Therefore prevalence of sensorimotor impairment was same as motor impairment whereas absolute sensory impairment was only $2 \%$ $(n=3)$. When compared to the patients without DPN, patients with DPN presented significantly $(p<0.05)$ higher age, higher diabetic duration and higher HbA1c (\%) level than the non-DPN patients. In our study no significant $(p>0.05)$ difference was found in case of BMI, systolic and diastolic blood pressure between DPN and non-DPN patients.

Table 1. Statement on sensory and motor neuropathy of type-2 diabetes patients $(n=150)$

\begin{tabular}{lcccc}
\hline Parameters & \multicolumn{3}{c}{ Type 2 diabetic patients } & \multirow{2}{*}{$p$-value } \\
\cline { 2 - 4 } & No. of respondents & Non-DPN (S + M) & DPN (S + M) & \\
\hline Age & 48.58 & $47.75 \pm 9.92$ & $52.10 \pm 6.75$ & 0.001 \\
Body mass index & 24.35 & $24.23 \pm 3.51$ & $24.68 \pm 4.30$ & 0.172 \\
Blood pressure (systolic) & 123.7 & $122.52 \pm 13.89$ & $125.75 \pm 15.50$ & 0.110 \\
Blood pressure (diastolic) & 75.57 & $75.46 \pm 12.11$ & $75.57 \pm 8.27$ & 0.810 \\
Duration of diabetes & 5.27 & $4.61 \pm 3.80$ & $8.05 \pm 5.01$ & 0.001 \\
HbA1c level & 9.42 & $8.92 \pm 1.88$ & $10.11 \pm 2.03$ & 0.001 \\
\hline
\end{tabular}

HbA1c $=$ Glycosylated hemoglobin, Male $=46 \%$, Female $=54 \%$, Non-DPN $=76 \%$, DPN $=24 \%, S=$ Sensory, $M=$ Motor.

As represented in Fig.1, at least one sensory function among vibration sensation, monofilament sensation, touch sensation, pain sensation, thermal sensation and position sensation was impaired in the participant confirming DPN. The most frequent impaired sensory function (21 patients) was monofilament sensation whereas, the least frequent impaired function was thermal sensation observed among 3 patients. 


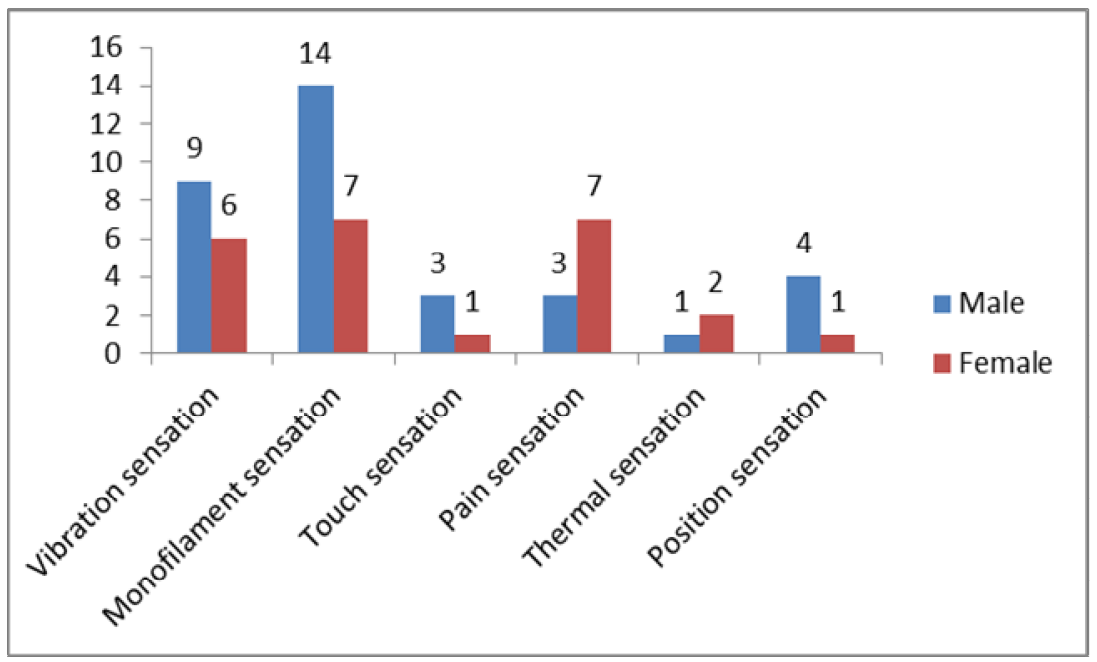

Fig. 1: Frequency of impaired sensory function in patients with DPN according to sex (among 22 males, and 14 females).

Fig. 2 shows the most frequency of reduced motor function in patients with DPN of the current study is muscle tone among 17 patients. Second most frequently reduced motor function was observed ankle jerk reflex and the number was 13 . Whereas least frequently reduced motor function was plantar response which was found only 4 patients.

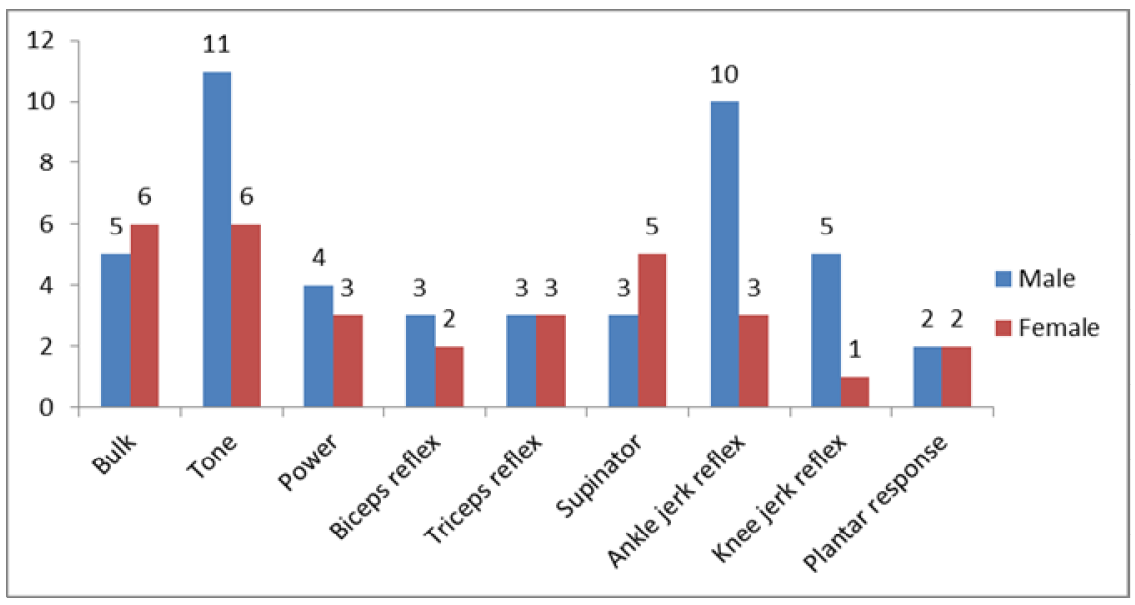

Fig. 2: Frequency of reduced motor function in patients with DPN according to sex (among 22 males, and 14 females). 
As shown in Fig. 3 compared to the sensory function, impairment of motor functions was more frequent in both sexes leading to DPN. The most frequently absence of motor function was observed in case of the ankle jerk reflex whereas plantar responses were the least. But summation of reduced and absence of ankle jerk reflexes were observed most frequently among all motor impairments.

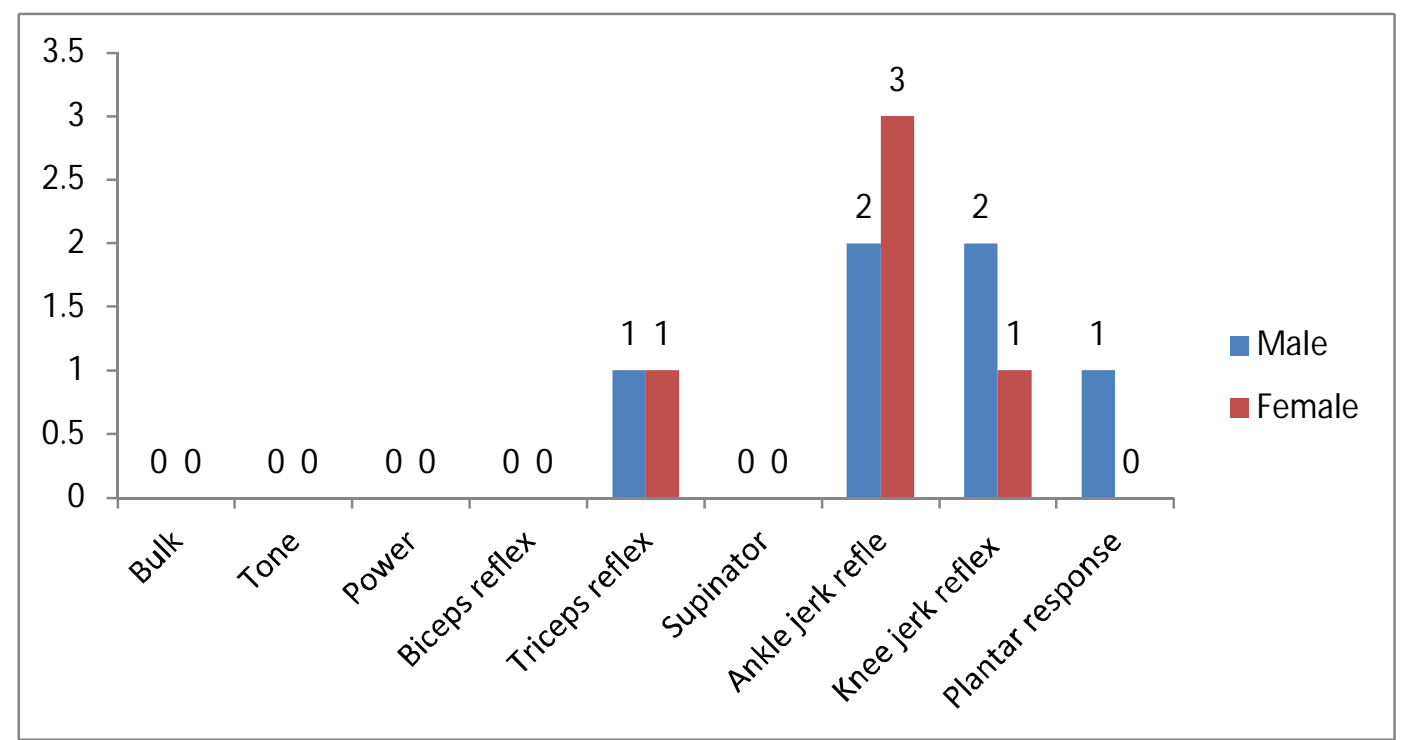

Fig. 3: Frequency of absence in motor function in patients with DPN according to sex (among 22 males, and 14 females).

\section{Discussion}

The present study investigated the association of HbA1c with DPN (sensory and motor) in type-2 diabetic patients. The study revealed that the increased HbA1c variability was found to be a significant and independent contributor to DPN. In this study, mean age of the DPN (sensory and motor) participants 52.10 \pm 6.75 years and mean duration of diabetes was $8.05 \pm 5.01$ years. A study in Bangladesh by Mørkrid et al (2010) reported that the prevalence of DPN was 19.7\% in type 2 diabetic patients (mean age in the DPN group: $55.1 \pm 10.5$ years, mean diabetes duration: $7.7 \pm 1.9$ years). This finding suggests that in Bangladesh, the mean age and mean duration of diabetes decreasing for DPN development but prevalence $(24 \%)$ is increasing. A research from a diabetic center in India recorded that the prevalence of neuropathy among outpatients with type 2 diabetes was $19.1 \%$ and the prevalence rate was lesser than observed in the current study (mean age in the DPN group: $62 \pm 8$ years, mean duration of diabetes: $12 \pm 8$ years) (Ashok et al. 2002). Diabetic complications occurred earlier in Bangladeshi subjects, both in terms of patient age and length of diabetes, as compared to the findings from India. The prevalence rate of DPN in Bangladesh is lower compared to European studies which have reported an overall DPN prevalence of $32.1 \%$ (mean age: 63 years, mean duration of diabetes: 6 years) (Young et al.1993); 35.4\% (mean age: 61.3 years, mean duration of diabetes: 9.7 years) (Cabezas-Cerrato 1998) and 60.0\% (mean age: $57.2 \pm 10.3$, mean duration of diabetes: $8.52 \pm 7.13$ years) (BÖRü et al. 2004) among type-2 diabetic hospital outpatients. UK studies 
have indicated a lower incidence of DPN in type-2 South Asian diabetic patients relative to European patients living in the UK, even after age adjustment (Abbott et al. 2005, Chaturvedi et al. 2002). This discrepancy, however, may be due to the diagnosis criteria used in these western studies that vary from the present research, as Mørkrid and associates have also indicated (Mørkrid et al. 2010).

The mean age of our subjects was 48.58 years, which may confirm that the diabetes population in this part of the world is relatively young compared to the West (Mørkrid et al. 2010, Hussain et al. 2005, Ramachandan et al. 1999). Our study found that the advanced age and longer duration of diabetes were important and significant risk factors for peripheral neuropathy. These results were consistent with findings of other studies (Mørkrid et al. 2010, Suljic et al. 2013, Agrawal et al. 2014). HbA1c, fasting blood glucose levels, and two hours after breakfast have been shown to be significant risk factors for peripheral neuropathy. Such observations are consistent with other research (Kumar et al. 2012, Agrawal et al. 2014). No significant correlation of systolic and diastolic blood pressure with peripheral neuropathy has been found (Ramchandran et al. 1999) and no significant association of hypertension with diabetic neuropathy has been recorded, although some are in comparison to this current research (Knuiman et al. 1986, Agrawal et al. 2014). However, in our case, we also found that there was no significant association of systolic and diastolic blood pressures with peripheral neuropathy. Several studies have shown that HbA1c may display a glycemic threshold for micro and macro vascular diabetes complications, indicating that it may also be important to categorize people at risk for various vascular complications (Sabanayagam et al. 2009, Zoungas et al. 2012, Hernandez et al. 2013). In this study, it was observed that increasing HbA1c categories above almost $9.0 \%$ were significantly associated with increased prevalence of DPN. The findings of this research were consistent with others (Sabanayagam et al. 2009) who indicated that there was a greater prevalence of peripheral neuropathy in increasing $\mathrm{HbA1C}$ groups. A similar correlation of $\mathrm{HbA1C}$ with neuropathy was also found in another study (Agrawal et al. 2014). The obvious HbA1c level threshold was 6.5\% for microvascular events (Zoungas et al. 2012). They also found that higher HbA1c levels were substantially correlated with higher risks of micro-vascular events in a log-linear fashion over thresholds. There was no important association between the mean HbA1c level and risks below these levels. There have been very few DPN events reported in the current analysis at HbA1c levels below $7.0 \%$ could be due to limited sample size, so the HbA1c levels below $7.0 \%$ may not be adequately measured. The assessment of HbA1c variability represents long term glycemic variability and may induce oxidative stress (Gorst et al. 2015). The precise mechanism by which diabetes develops neuropathy has not been clearly explained, but peripheral nerve damage is believed to be involved with elevated levels of advanced glycation end products (AGE) and protein kinase $C$ (PKC) due to chronic hyperglycemia. Microscopic vascular disruption is generated by oxidative stress caused by AGE, which impedes blood flow to the peripheral nerves (Morales-Vidal et al. 2012). The relative risk of microvascular complication decreased by $37 \%$, diabetes-related mortality by $21 \%$ and myocardial infarction by $14 \%$ with every $1 \%$ reduction of $\mathrm{HbA1c}$ (Stratton et al. 2000). Thus, variability of $\mathrm{HbA1c}$ can be a possible factor associated with DPN risk, especially sensory and motor neuropathy. 


\section{Conclusion}

Findings of this study suggest that increasing HbA1c level is significantly associated with increased prevalence of DPN specially sensory and motor neuropathy and the risk increases markedly at HbA1c levels $\geq 8.9 \%$. The prevalence and risk of DPN also increased with advanced age and longer duration of diabetes. Careful assessment of the risk factors of DPN among diabetic patients, and control of HbA1c level and appropriate preventive measures are thus recommended.

\section{References}

Abbott CA, Garrow AP, Carrington AL, Morris J, Van Ross ER and Boulton AJ (2005). Foot ulcer risk is lower in SouthAsian and African-Caribbean compared with European diabetic patients in the UK: the North-West diabetes foot care study. Diabetes Care, 28(8): 1869-1875.

Agrawal RP, Ola V, Bishnoi P, Gothwal S, Sirohi P and Agrawal R (2014). Prevalence of micro and macrovascular complications and their risk factors in type-2 diabetes mellitus. Journal of the Assoc. Physicians of India. 52: 45-48.

Ashok S, Ramu M, Deepa R and Mohan V (2002). Prevalence of neuropathy in type 2 diabetic patients attending a diabetes centre in South India. J Assoc Physicians India, 50:546-50.

BÖRü ÜT, Alp R, Sargin H, Koçer A, Sargin M, LüLECl A and Yayla A (2004). Prevalence of peripheral neuropathy in type 2 diabetic patients attending a diabetes center in Turkey. Endocrine Journal, 51(6): 563-567.

Boulton AJ, Cavanagh PR and Rayman G (2006). The foot in diabetes, 4th Edition. John Wiley and Sons Ltd. http://www.textbookofdiabetes.com/references/c44.asp

Boulton AJ, Malik RA, Arezzo JC and Sosenko JM (2004). Diabetic somatic neuropathies. Diabetes Care, 27: 1458-1486.

Boulton AJ, Vinik Al, Arezzo JC, Bril V, Feldman EL, Freeman R, Malik RA, Maser RE, Sosenko JM and Ziegler D (2005). American Diabetes Association Diabetic neuropathies: a statement by the American diabetes association. Diabetes Care, 28: 956-962.

Cabezas-Cerrato J (1998). The prevalence of clinical diabetic polyneuropathy in Spain: a study in primary care and hospital clinic groups. Diabetologia, 41(11): 1263-1269.

Carrington AL, Shaw JE, Van Schie CH, Abbott CA, Vileikyte L and Boulton AJ (2002). Can motor nerve conduction velocity predict foot problems in diabetic subjects over a 6-year outcome period? Diabetes Care, 25: 2010-2015.

Chaturvedi N, Abbott CA, Whalley A, Widdows P, Leggetter SY and Boulton AJ (2002). Risk of diabetes related amputation in South Asians vs. Europeans in the UK. Diabet Med., 19: 99-104.

Gorst C, Kwok CS, Aslam S, Buchan I, Kontopantelis E, Myint PK, Heatlie G, Rutter MK, Loke Y and Mamas MA. (2015). Long-term glycemic variability and risk of adverse outcomes: a systematic review and meta-analysis. Diabetes Care, 38(12): 2354-2369.

Hernandez D, Espejo-Gil A, Bernal-Lopez MR, Mancera-Romero J, Baca-Osorio AJ, Tinahones FJ, Armas-Padron AM, Ruiz-Esteban P, Tores A and Gomez-Huelgas R (2013). Association of HbA1c and cardiovascular and renal disease in an adult Mediterranean population. BMC Nephrology, 14: 151

Hussain A, Rahim MA, Azad Khan AK, Ali SMK and Vaaler S (2005). Type 2 diabetes in rural and urban population: diverse prevalence and associated risk factors in Bangladesh. Diabetic Medicine, 22(7): 931-936

IDF Diabetes Atlas- 9th edition, 2019. https://www.diabetesatlas.org/en.

International Expert Committee (2009). International expert committee report on the role of the A1C assay in the diagnosis of diabetes. Diabetes Care, 32(7): 1327-1334.

Knuiman MW, Welborn TA, McCann VJ, Stanton KG and Constable IJ (1986). Prevalence of diabetic complications in relation to risk factors. Diabetes, 35: 1332-39. 
Kumar HKVS, Kota SK, Basile A and Modi KD (2012). Profile of microvascular disease in type 2 diabetes in a tertiary health care hospital in India. Ann Med Health Sci Res. 2(2): 103-08.

Martin CL, Albers JW and Pop-Busui R (2014). Neuropathy and related findings in the diabetes control and complications trial/epidemiology of diabetes interventions and complications study. Diabetes Care, 37(1): 31-38.

Morales-Vidal S, Morgan C, McCoyd M and Hornik A (2012). Diabetic peripheral neuropathy and the management of diabetic peripheral neuropathic pain. Post Grad Med., 124:145-53.

Mørkrid K, Ali L and Hussain A (2010). Risk factors and prevalence of diabetic peripheral neuropathy: a study of type 2 diabetic outpatients in Bangladesh. International Journal of Diabetes in Developing Countries, 30(1): 11-17

Ramachandran A, Snehalatha C, Satyavani K, Latha E, Sasikala R and Vijay V (1999). Prevalence of vascular complications and their risk factors in type 2 diabetes. The Journal of the Association of Physicians of India, 47(12): 1152-1156.

Sabanayagam C, Liew G, Tai ES, Shankar A, Lim SC, Subramaniam T and Wong TY (2009). Relationship between glycated haemoglobin and microvascular complications: is there a natural cut-off point for the diagnosis of diabetes?. Diabetologia, 52(7):1279.

Shaw JE (1999). The epidemiology of diabetic neuropathy. Diabetes Rev., 7: 245-252.

Stratton IM, Adler AI, Neil H A, Matthews DR, Manley SE, Cull CA, Hadden D, Turner RC and Holman RR (2000). Association of glycaemia with macrovascular and microvascular complications of type 2 diabetes (UKPDS 35). BMJ Clinical Research, 321(7258): 405-412.

Suljic E, Kulasin I and Alibegovic V (2013). Assessment of diabetic polyneuropathy in inpatient care: fasting blood glucose, HbA1c, electroneuromyography and diabetes risk factors. Acta Inform. Med., 21(2): 123-26.

Tesfaye S, Vileikyte L, Rayman G, Sindrup S, Perkins B, Baconja M, Vinik A and Boulton A (2011). On behalf of the Toronto expert panel on diabetic neuropathy painful diabetic peripheral neuropathy: consensus recommendations on diagnosis, assessment and management. Diabetes Metab Res Rev., 27: 629-638.

Thibault V, Belanger M, LeBlanc E, Babin L, Halpine S, Greene B and Mancuso M (2016). Factors that could explain the increasing prevalence of type 2 diabetes among adults in a Canadian province: A critical review and analysis. Diabetology \& Metabolic Syndrome, 8: 71.

Wild SH, Roglic G, Green A, Sicree R and King H (2004). Global prevalence of diabetes: estimates for the year 2000 and projections for 2030: response to Rathman and Giani. Diabetes Care, 27(10): 2569-2570.

Young MJ, Boulton AJ, MacLeod AF, Williams DR and Sonksen PH (1993). A multicentre study of the prevalence of diabetic peripheral neuropathy in the United Kingdom hospital clinic population. Diabetologia, 36: 150-54.

Zargar AH, Wani Al, Masoodi SR, Laway BA and Bashir MI (1999). Mortality in diabetes mellitus- data from a developing region of the world. Diabetes Res Clin Pract., 43: 67-74.

Zoungas S, Chalmers J, Ninomiya T, Li Q, Cooper ME, Colagiuri S, Fulcher G, Galan BE de Harrap S, Hamer P, MacMahon S, Marre M, Poulter N, Patel A, Neal B, Woodward M and Heller S (2012). Association of HbA1c levels with vascular complications and death in patients with type 2 diabetes: evidence of glycaemic thresholds. Diabetologia, 55(3): 636-643. 